\title{
Endovascular versus medical management of type B intramural hematoma: a meta-analysis
}

\author{
Adam Chakos ${ }^{1,2}$, Tisha Twindyawardhani ${ }^{1}$, Arturo Evangelista ${ }^{3,4}$, Giuliana Maldonado ${ }^{3}$, \\ Gabriele Piffaretti ${ }^{5}$, Tristan D. Yan ${ }^{1,2,6}$, David H. Tian ${ }^{1,2,7}$ \\ ${ }^{1}$ The Collaborative Research (CORE) Group, ${ }^{2}$ Faculty of Medicine and Health Sciences, Macquarie University, Sydney, Australia; ${ }^{3}$ Servei de \\ Cardiologia, Hospital Vall d'Hebron, VHIR, CIBER-CV, Barcelona, Spain; ${ }^{4}$ Instituto del Corazón, Quironsalud Teknon, Barcelona, Spain; \\ ${ }^{5}$ Department of Medicine and Surgery, University of Insubria School of Medicine, ASST Settelaghi Circolo University Teaching Hospital, Varese, \\ Italy; ${ }^{6}$ Department of Cardiothoracic Surgery, Royal Prince Alfred Hospital, Sydney, Australia; ${ }^{7}$ Royal North Shore Hospital, Sydney, Australia \\ Correspondence to: Adam Chakos. The Collaborative Research (CORE) Group, Macquarie University, Sydney, Australia. \\ Email: adam.chakos@outlook.com.
}

Background: Aortic intramural hematoma constitutes one of the three classifications of acute aortic syndrome (AAS). Type B intramural hematoma (IMH-B) is localized to the descending thoracic aorta and can be managed through medical, endovascular or surgical means. Data comparing contemporary management with thoracic endovascular aortic repair (TEVAR) versus traditional medical management (MM) is sparse and only moderate strength recommendations for TEVAR are provided in guidelines. This meta-analysis aimed to pool available data from comparative studies between TEVAR and MM and examine differences in outcomes.

Methods: Literature search of electronic medical databases was conducted to identify studies comparing TEVAR and MM for management of IMH-B. Data extraction from studies fulfilling the inclusion criteria was performed by two authors and meta-analysis using a random-effects model applied to pool baseline data and examine risk ratios (RR) for management outcomes.

Results: Of the initial 2,349 studies, nine studies were identified for analysis. There were 161 TEVAR patients and 166 who were medically managed. The mean age of the cohort was 62.2 years [95\% confidence interval (CI): 55.8-68.7 years]. Patients with complicating features of IMH-B at presentation were more likely to appear in the TEVAR group, with more penetrating atheromatous ulcer (PAU) [risk difference (RD), 0.565, 95\% CI: 0.240-0.889, P=0.001], ulcer-like projection (ULP) (RD 0.240, 95\% CI: 0.965-0.384, $\mathrm{P}=0.001$ ), and greater IMH size (mean difference, MD $5.47 \mathrm{~mm}, 95 \% \mathrm{CI}: 0.320-10.6, \mathrm{P}=0.037$ ). There was no statistical difference between TEVAR and MM for the primary endpoints of aortic-related death (RR 0.535, 95\% CI: 0.191-1.5, P=0.234) or IMH-B regression (RR 1.25, 95\% CI: 0.859-1.81, P=0.246). Of the secondary endpoints, TEVAR had both significantly less dissection during follow-up (RR 0.295, 95\% CI: 0.0881-0.989, P=0.048) and less rupture during follow-up (RR 0.206, 95\% CI: 0.0462-0.921, P=0.039).

Conclusions: A small number of series comparing TEVAR and MM for management of IMH-B are available and random-effects meta-analysis did not reveal any statistically significant difference between treatments for aortic related death or IMH-B regression at a mean follow-up of 37 months. TEVAR was found to be associated with lower risk of dissection and lower risk of rupture during follow-up. Baseline data meta-analysis showed patients with complicating features of PAU, ULP, and larger IMH size were more likely to be managed with TEVAR.

Keywords: Intramural hematoma; type B; thoracic endovascular aortic repair (TEVAR); medical management

Submitted Jun 11, 2019. Accepted for publication Jun 24, 2019.

doi: $10.21037 /$ acs.2019.06.11

View this article at: http://dx.doi.org/10.21037/acs.2019.06.11 


\section{Introduction}

Aortic intramural hematoma (IMH) is defined by hemorrhage within the aortic media and is one of the three subtypes of acute aortic syndrome (AAS) $(1,2)$. Aortic dissection comprises around $85-95 \%$ of AAS, with IMH making up $5-15 \%$ and penetrating atheromatous ulcer (PAU) around $5 \%$. Traditionally, IMH has been attributed to rupture of the vasa vasorum, however, improvements in imaging and reporting have led to conclusions that true lumen communication via micro-intimal tears may also be causative $(3,4)$. Complicated cases of type B intramural hematoma (IMH-B) are defined by ongoing pain, increasing diameter of the lesion or presence of ulcer-like projections (ULP) (5).

IMH is classified according to the Stanford type A and B system for aortic dissection, with IMH-A originating in the ascending aorta and IMH-B originating in the descending aorta. Management is typically derived from that for aortic dissection and while class I recommendations exist for surgical treatment of IMH-A, only class IIa (moderate) recommendations exist for the management of $\mathrm{IMH}-\mathrm{B}$, which can consist of medical management alone or with the addition of thoracic endovascular aortic repair (TEVAR) $(6,7)$.

While single-armed institutional reports of medical or endovascular management of IMH-B have been published, few comparative series are available in the literature. Given uncomplicated IMH-B lesions can progress to complicated lesions, some centers prefer broad application of TEVAR, citing it as a relatively low-risk technique $(8,9)$ that would benefit both complicated and uncomplicated IMH-B $(10,11)$. Other centers prefer to use TEVAR as a second-line option after medical management $(7,12)$. The objective of this study was to use data from comparative studies to examine potential differences in outcomes for IMH-B treated with medical management (MM) versus endovascular therapy (TEVAR).

\section{Methods}

\section{Literature search}

The electronic medical databases Medline, Embase and PubMed were queried from dates of inception until December 2018. The terms ("intramural hematoma" OR "intramural haematoma" OR "IMH”) OR (("aorta" OR "aortic") AND ("hematoma" OR "haematoma")) AND ("endovascular" OR "medical treatment" OR "endoluminal" OR "medical therapy" OR "medical management"), were used.

Literature search of the results and subsequent data collection from original studies comparing medical and endovascular management in type B IMH was performed independently by two researchers (A Chakos and T Twindyawardhani), with differences in results resolved by consensus. Inclusion criteria were studies reporting primary comparative data between medically-managed and TEVAR-managed IMH-B with at least 10 patients per treatment arm. Animal studies, reviews, case-reports, editorials and conference abstracts were excluded. Studies with pooled results for outcomes of medical management and endovascular treatment results were also excluded. A PRISMA diagram detailing the literature search is provided (Figure S1).

Primary endpoints included aortic-related death and IMH-B regression. Aortic-related death was defined as death attributable to an aortic cause during the initial admission or follow-up, and IMH-B regression was defined as a reduction in IMH size. Secondary endpoints included early death (in-hospital or 30-day), follow-up requirement for secondary intervention [after the initial admission period, defined as two weeks from presentation $(10,12)]$, follow-up dissection, and follow-up rupture. Secondary endpoints were evaluated where they were reported by half of the included studies.

\section{Quality analysis}

Individual study quality appraisal was completed using a 19-point metric based on the Canadian Institute of Health Economics quality analysis (13). The metric examined domains including study design, how completely study populations were described, clarity provided for interventions, and completeness of outcome and followup reporting. Total scores were then tallied and where included, studies scoring 10 or below were graded as standard quality, those scoring 11-13 were graded moderate quality, and those scoring 14-19 were graded as high quality.

\section{Treatment definitions}

Medical management protocols varied between institutions but typically included administration of various antihypertensive agents and management of pain, as per the Class I recommendations of the European Society of Cardiology (ESC) guidelines $(6,8,12)$. TEVAR was typically 
indicated in complicated cases of IMH-B; IMH expansion (despite medical therapy), impending rupture, uncontrolled hypertension, end-organ damage, refractory pain, or development of an intimal tear on CT $(3,6,7,14)$.

Where MM patients received TEVAR after admission, this was defined as a secondary intervention where it occurred outside the acute phase, defined as two weeks after presentation $(10,14)$.

Intramural hematoma regression was defined as a reduction in the size of the hematoma $(7,12)$. Complete aortic remodeling was reported in addition to IMH-B regression in some studies $(7,10,12,14)$.

\section{Statistical analysis}

Data from included studies was extracted by two independent researchers (A Chakos and $\mathrm{T}$ Twindyawardhani). Where data was expressed as median and interquartile range, it was converted to mean and standard deviation using the methods of Wan et al. (15) to allow for pooling. Pooling was performed using meta-analysis of proportions or means. Differences in baseline data were summarized as risk difference and mean difference for proportion and continuous data, respectively, with $95 \%$ confidence intervals (95\% CI) provided.

Outcomes for medical management and TEVAR cohorts were compared and risk ratios (RR) calculated with 95\% confidence intervals. A random effects model was applied for all analyses to account for between-study variance that would be inevitable with patient selection, procedural, and care differences not accounted for in institutional series. Studies with zero-event outcomes in both arms were not weighted in meta-analysis.

Publication bias was examined with funnel plots and also by Egger's test. Heterogeneity amongst studies was assessed using the $\mathrm{I}^{2}$ statistic, with consideration of $\mathrm{I}^{2}$ confidence intervals (16). Potential sources of heterogeneity were explored, including with the aid of an L'Abbe plot, Baujat plot, and a leave-one-out sensitivity analysis conducted to identify studies contributing most to heterogeneity and inconsistency of effect measure (17).

Two-tailed $\mathrm{P}$ values $<0.05$ were deemed as significant. All statistics were performed with $R$ [R Foundation for Statistical Computing, Vienna, Austria (18)].

\section{Results}

Literature search identified 2,476 records from which
289 full-text articles were reviewed: 9 studies were found to fit the inclusion criteria (PRISMA diagram Figure S1) (7-12,14,19,20). The nine comparative studies contained 327 patients with IMH-B, 166 treated with medical management alone, and 161 treated with TEVAR. Mean follow-up was 37.3 months, 95\% CI: 29.0-45.5], reported for $\mathrm{n}=279$ patients. Study quality was assessed as high for 5 studies, moderate for 2 studies, and standard for 2 studies (Table S1).

Overall patient cohort mean age was 62.2 years $(95 \%$ CI: 55.8-68.7 years), with 67\% males (95\% CI: 61.0-72.5). Where reported, the majority of patients presented with hypertension (86\%, 95\% CI: 75.2-92.6\%) and symptomatically (93\%, 95\% CI: 83.1-97.3\%).

Comparison of baseline risk data between groups (Table 1) showed TEVAR patients had a higher prevalence of PAU (risk difference, RD 0.565, 95\% CI: 0.240-0.889, $\mathrm{P}=0.001$ ), ulcer like projection (RD $0.240,95 \% \mathrm{CI}$ : $0.097-0.384, \mathrm{P}=0.001$ ), and greater mean $\mathrm{IMH}$ size (mean difference, MD 5.47, 95\% CI: 0.320-10.6, P=0.037). However, of those in the TEVAR group, PAU and ULP were not present in at least $50 \%$ of cases. Risk and mean difference for other baseline risk parameters did not reach statistical significance (baseline risk data from individual studies is reported in full in Table S3).

Intraoperative data was only reported for 3 studies $(7,8,10)$ and is presented in Table $S 4$. The paucity of intraoperative data precluded pooling.

There was no statistically significant difference between TEVAR and MM groups for the primary endpoints of aortic-related death (RR 0.535, 95\% CI: 0.191-1.5], $\mathrm{P}=0.234)$ or $\mathrm{IMH}-\mathrm{B}$ regression ( $\mathrm{RR} 1.25,95 \% \mathrm{CI}$ : $0.859-1.81, \mathrm{P}=0.246$; Figure 1, Table 2). IMH-B regression data was collected as distinct from "complete aortic remodeling", which some studies additionally reported $(7,10,12,14)$.

Of the secondary endpoints (Table 2), TEVAR patients had significantly less dissection (RR 0.295, 95\% CI: 0.088 $0.989, \mathrm{P}=0.048$; Figure 2) and less rupture during follow-up (RR 0.206, 95\% CI: 0.046-0.921, $\mathrm{P}=0.039$; Figure 2). There was no significant difference in early death or requirement for second intervention (Figures S2,S3). Individual study endpoint data is presented in Table $S 5$.

Heterogeneity was low for most endpoints, except for IMH regression: $\mathrm{I}^{2}=92 \%$, and requirement for second intervention: $\mathrm{I}^{2}=65 \%$. However, generalisability of results may remain limited as some endpoints were incompletely reported across studies and some $\mathrm{I}^{2}$ confidence intervals 


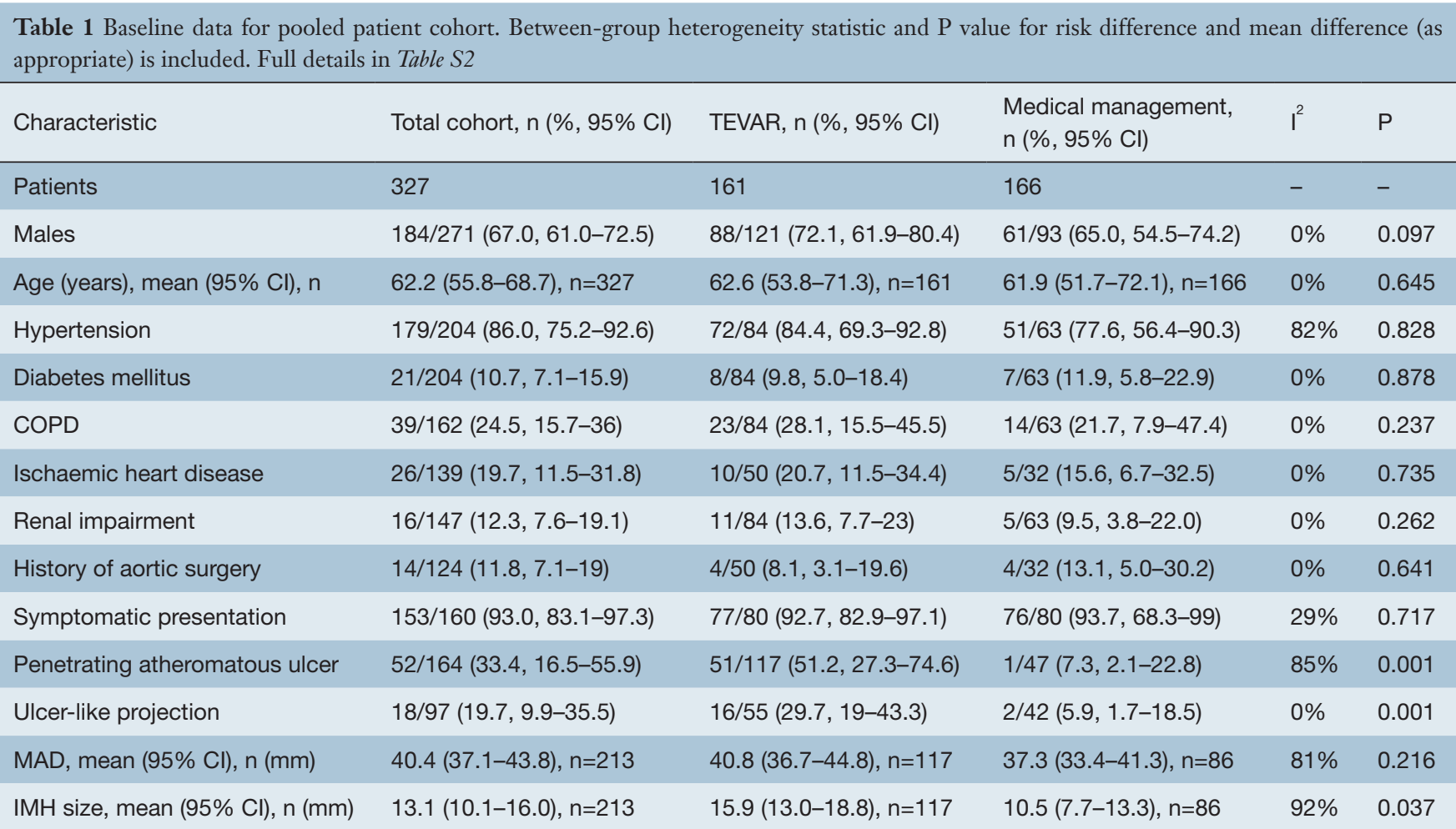

COPD, chronic obstructive pulmonary disease; MAD, maximum aortic diameter; IMH, intramural hematoma; TEVAR, transcatheter endovascular aortic repair; $\mathrm{Cl}$, confidence interval; $\mathrm{I}^{2}$, heterogeneity statistic; $\mathrm{P}$, alternate hypothesis probability.

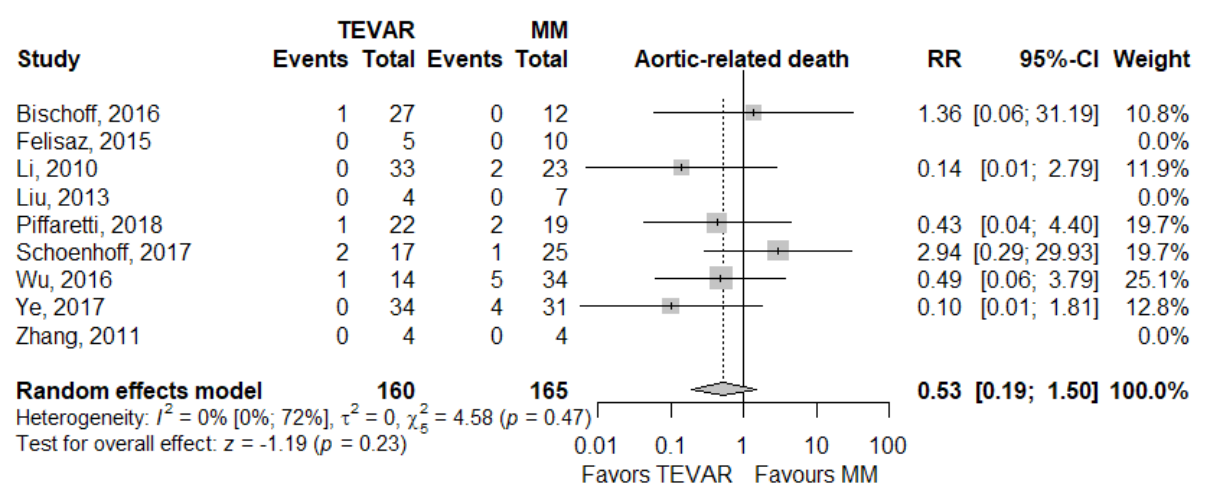

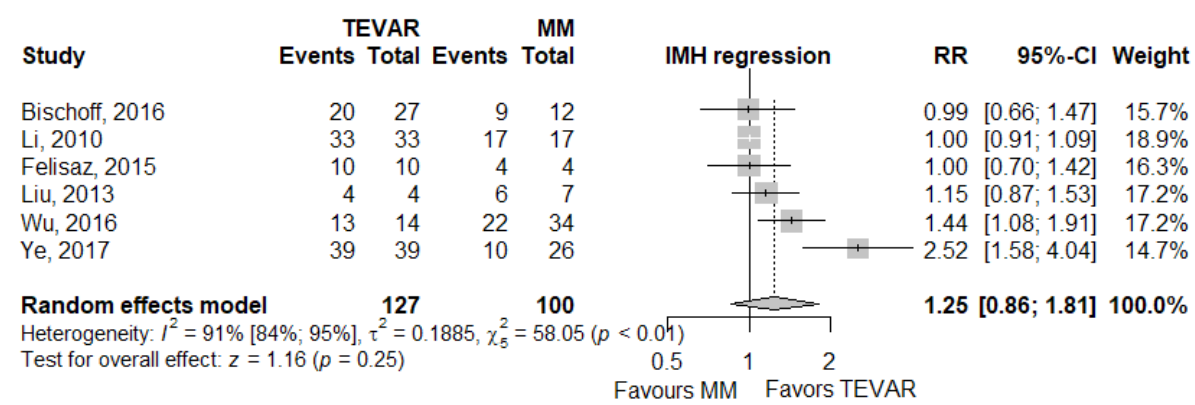

Figure 1 Relative risk/risk ratio for primary endpoints of aortic-related death and IMH-B regression. IMH-B, type B intramural hematoma. 


\begin{tabular}{|c|c|c|c|c|c|}
\hline $\begin{array}{l}\text { IMH regression at } \\
\text { follow-up }\end{array}$ & $\begin{array}{l}200 / 252(80.9,67.2-89.8, \\
\left.I^{2}=68 \%\right)\end{array}$ & $\begin{array}{l}\text { 119/127 (92.9, 78.6- } \\
\left.97.9, I^{2}=52 \%\right)\end{array}$ & $\begin{array}{l}68 / 100(71.0,49.9-86.7, \\
\left.I^{2}=65 \%\right)\end{array}$ & $\begin{array}{l}1.25(0.859-1.810) \\
I^{2}=91 \%\end{array}$ & 0.246 \\
\hline Early death & $\begin{array}{l}4 / 327(3.8,2.1-6.8, \\
\left.I^{2}=0 \%\right)\end{array}$ & $\begin{array}{l}2 / 161(4.1,1.8-9.1, \\
\left.I^{2}=0 \%\right)\end{array}$ & $\begin{array}{l}2 / 166(3.6,1.6-8.0, \\
\left.I^{2}=0 \%\right)\end{array}$ & $\begin{array}{l}0.821(0.170-3.970) \\
I^{2}=0 \%\end{array}$ & 0.806 \\
\hline $\begin{array}{l}\text { Secondary } \\
\text { intervention required }\end{array}$ & $\begin{array}{l}40 / 260(18.7,10.4-31.3 \\
\left.I^{2}=65 \%\right)\end{array}$ & $\begin{array}{l}10 / 139(8.7,2.2-28.5 \\
\left.I^{2}=69 \%\right)\end{array}$ & $\begin{array}{l}30 / 121(27.1,15.6-42.7 \\
\left.I^{2}=57 \%\right)\end{array}$ & $\begin{array}{l}0.308(0.066-1.450) \\
I^{2}=67 \%\end{array}$ & 0.136 \\
\hline Follow-up dissection & $\begin{array}{l}17 / 256(10.0,6.5-15.0, \\
\left.I^{2}=0 \%\right)\end{array}$ & $\begin{array}{l}4 / 138(5.8,2.6-12.4 \\
\left.I^{2}=0 \%\right)\end{array}$ & $\begin{array}{l}13 / 118(12.6,7.6-20.2 \\
\left.I^{2}=0 \%\right)\end{array}$ & $\begin{array}{l}0.295(0.088-0.989) \\
I^{2}=0 \%\end{array}$ & 0.048 \\
\hline
\end{tabular}

TEVAR, thoracic endovascular aortic repair; MM, medical management; $\mathrm{Cl}$, confidence interval; RR, risk ratio/relative risk; ${ }^{2}$, heterogeneity; $\mathrm{P}$ probability of null hypothesis.

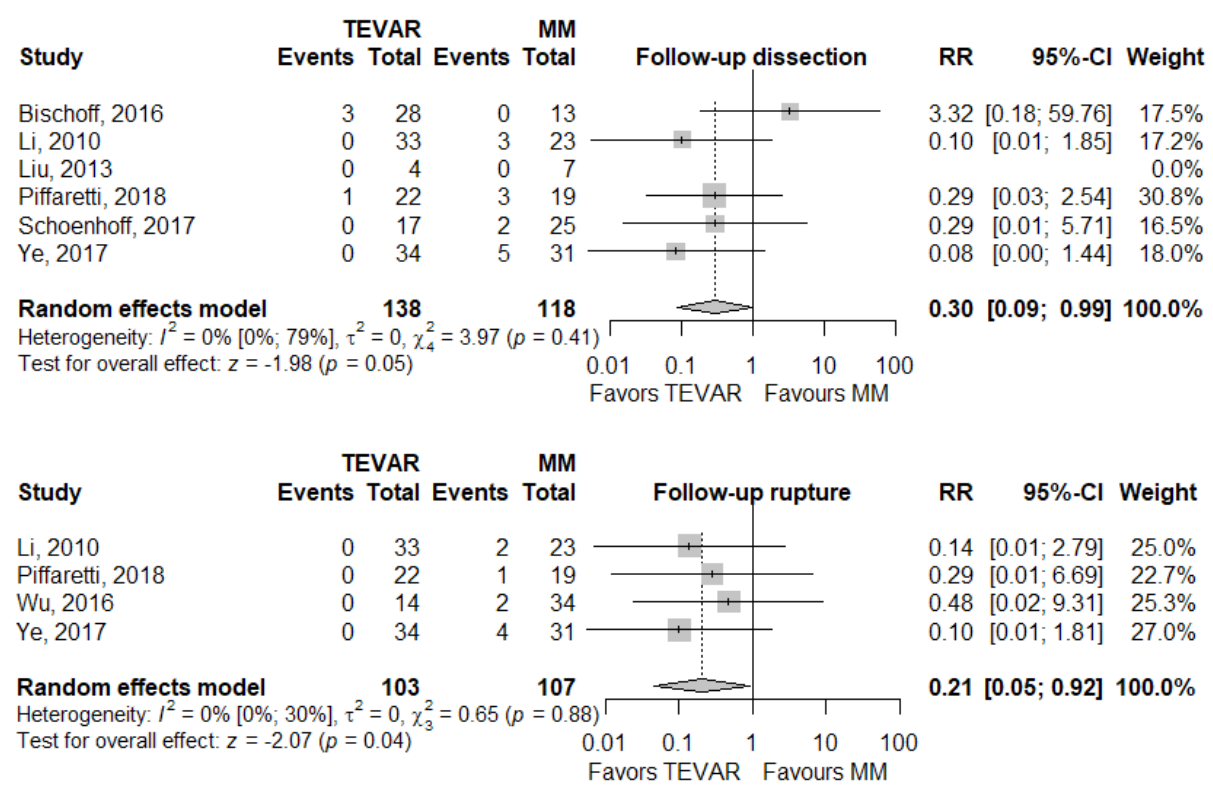

Figure 2 Relative risk/risk ratio for secondary endpoints reaching significance: follow-up aortic dissection and follow-up aortic rupture.

were wide (Table S2).

Funnel plots were visually inspected for asymmetry as a measure of publication bias and Egger's test was applied (Figures S4,S5). The Egger's test null hypothesis of plot symmetry (i.e., publication bias not likely to be present) was not rejected for any outcome, however, visual inspection suggested asymmetry for the co-primary endpoint of IMH-B regression.

\section{Discussion}

This meta-analysis pooled results from nine institutional 
series comparing endovascular and medical management alone in the treatment of type B aortic intramural hematoma. Meta-analysis showed no statistically significant difference between TEVAR and MM for the primary endpoints of aortic-related death or IMH-B regression. Aortic dissection at follow-up and aortic rupture at followup was significantly reduced in the TEVAR group. Baseline data was incompletely reported but where reported, pooling showed the majority of patients treated for IMH-B were hypertensive and symptomatic at presentation. Patients in the TEVAR group had a statistically significantly greater prevalence of PAU and ULP at baseline, as well as greater $\mathrm{IMH}$ size, though PAU and ULP were not present in at least $50 \%$ of patients managed with TEVAR.

Results from the current study are consistent with single-arm reviews conducted in consensus statements and guidelines $(5,6,21)$. An interdisciplinary consensus statement on the management of $\mathrm{IMH}-\mathrm{B}$ and PAU reviewed 18 publications to find that the 30-day mortality for IMH-B was $3.9 \%$, and $4.6 \%$ and $3.4 \%$ for TEVAR and MM respectively (5). These acute phase mortality results support those from the present analysis for total, TEVAR, and MM cohorts; $3.8 \%, 4.1 \%$ and $3.6 \%$, respectively. Clear results for aortic-related mortality in individual TEVAR and MM groups at follow-up were not available from other studies for comparison.

The follow-up dissection rate of $10.0 \%$ (95\% CI: 6.49 $15 \%)$ in this meta-analysis is consistent with the $3-14 \%$ conversion rate to aortic dissection cited by the review in the most recent ESC guidelines (21). Additionally, findings from the present analysis of significantly lower risk of dissection and rupture at follow-up with TEVAR add weight to the conclusions of individual studies attributing low rates of adverse aortic events at follow-up and favorable aortic remodelling to TEVAR management $(8,9,12,20)$. However, some studies found higher rates of dissection and secondary intervention occurred with TEVAR (7). Hence, TEVAR should be applied in the context of considered clinical and radiological findings and with an eye to the possibility of technical challenges and complications of endovascular therapy in a potentially fragile vessel.

While guidelines agree that initial medical therapy under careful surveillance to control aortic wall stress is indicated in all IMH-B $(5,6,21,22)$, the role for TEVAR is less clear. A 2010 multi-disciplinary group guideline (including the American Heart Association and the Society of Thoracic Surgeons) recommends treatment of IMH-B as per aortic dissection of the same segment (level IIa recommendation) (21). However, the 2010 ESC guidelines are more specific, advising TEVAR should be considered (level IIa recommendation) for IMH-B complicated by recurrent pain, expansion, periaortic hematoma, and/or intimal disruption (6). A 2014 interdisciplinary expertpanel consensus statement on treatment of IMH-B also recommends TEVAR for complicated IMH-B in the acute phase and provides a broader definition of complicated lesions, including those associated with persistent chest pain, hemodynamic instability, periaortic hemorrhage, presence of ULP, diameter $>55 \mathrm{~mm}$, and/or rapid expansion (5). The results of the present analysis did not find a significant difference in late aortic death between TEVAR and medical management, reflecting the guideline level II recommendations of consideration, rather than clear indication, for TEVAR in complicated IMH-B.

This review is limited by several factors. Firstly, relatively few studies contain detailed TEVAR data, with comparative studies even more scarce in the literature $(5,8)$. Randomized trials are not available, and for the most part, included comparative studies were single-center, retrospective series, with only one multicentre study (8) and three prospective studies $(7,9,11)$. This lack of RCTs means that patient selection for TEVAR or MM introduces a likely source of bias, as sicker patients may have been confined to non-operative management, while more complex IMH typically appeared in the TEVAR group. Heterogeneity of lesions within cohorts is acknowledged as a difficulty of collating the available data for IMH-B (8), however, the present analysis found that heterogeneity point estimates in pooled baseline data and outcomes were typically low-moderate but this should be considered in the context of often wide $\mathrm{I}^{2}$ confidence intervals. Forest plots of outcome data show there were outlying studies for some outcomes, however, careful review of outlying studies revealed no reason for their exclusion, nor did sensitivity analysis demonstrate any change in overall findings of statistical significance.

\section{Conclusions}

Meta-analysis of nine studies containing 161 TEVAR patients and 166 medically managed patients for IMH-B did not find a significant difference in aortic-related death and IMH-B regression. TEVAR was associated with a significantly reduced risk of aortic dissection or aortic rupture during the same follow-up. Patients with complicating features of PAU, ULP and greater IMH size 
were more likely to be managed with TEVAR.

\section{Expert opinion: unlocking the mystery of type B IMH treatment}

\section{Evangelista, Maldonado}

Over the last 20 years, IMH of the aorta has become increasingly recognized as a pathologic entity distinct from aortic dissection. Despite better understanding of this disease, a consensus of optimal management strategies has not yet been established. One aspect of IMH that confounds attempts to set indications for intervention is the significant dynamic changes in the morphologic appearance of aortic IMH. Thus, depending on the exact time after symptom onset an imaging "snapshot" is taken, the findings may be interpreted differently from those obtained only hours before or after the present study. Although this metaanalysis found no differences in survival of patients with type B IMH treated medically or by TEVAR, those treated by the latter had both significantly less dissection and aortic rupture during follow-up. Logically, patients with complicating features of IMH-B at presentation were more frequent in the TEVAR group which included more PAU, ulcer-like projections and larger IMH size. Several studies have shown that IMH evolves with aorta dilation or aortic dissection in at least $50 \%$ of cases. Some of the current predictive factors of disease progression are: associated ulcer or intimal erosion in the acute phase, maximum aortic diameter $\geq 50 \mathrm{~mm}$ on initial CT scan, persistent pain, progressive maximum aortic wall thickness and enlarging aortic diameter. In some studies of this meta-analysis, clinical and imaging predictors of complications were not homogeneously considered. This point is crucial in a disease where $40 \%$ of cases evolve with no clinical complications and complete IMH regression without aorta dilation. Thus, although the cumulative risk of a conservative management policy is not clearly defined for uncomplicated type B IMH, there exists no clear advantage over an operative strategy. Most notably, a penetrating aortic ulcer in an acutelysymptomatic patient or an unstable or enlarging distal ulcer associated with type B IMH should be treated more aggressively. Acute focal intimal disruptions, whether due to atherosclerotic ulcers or not, should be considered for TEVAR. Subacute or chronic focal intimal disruptions may be treated more conservatively. IMH with tiny intimal disruption should, however, be followed closely in the first year after onset, as they may progress to focal intimal disruptions. As the mechanical properties of IMH change during follow-up, the timing of TEVAR has implications for the environment in which the stent-graft is deployed. The convenience of sealing completely within an intramural hematoma should be carefully considered given the potentially higher risk of retrograde type A dissection, especially during the acute phase. Further research is necessary and should focus on providing a stratified risk model coupled with a natural history assessment. In the meantime, uncomplicated type B IMH are optimally treated with medical management and TEVAR is reserved for patients with complications and requires an experienced team who can identify patient-specific challenges that increase the risk of the procedure.

\section{Expert opinion: the Devil hides in the details}

\section{Piffaretti}

Systematic review and meta-analysis effectively summarize what the available literature offers in terms of "daily practice" in the "real world". One of the most interesting points in this study is the absence of significant difference between best medical treatment (BMT) and TEVAR regarding aortic-related mortality or acute IMH-B regression.

Interpreting numbers into clinical scenarios is sometimes debatable; the glass can be seen as half-full or halfempty. First, in previous personal experience, IMH-B has demonstrated an unpredictable, rapid evolution characterized by lesion progression and ulcer-like appearanace in $47 \%$ of cases receiving BMT alone (23). In this meta-analysis, Chakos et al. pointed out that $50 \%$ of the cases of IMH-B which underwent TEVAR had no ulcer-like projection, but this means the other $50 \%$ did and this has been reported to be a significant predictor for late aortic events (24). Secondly, the fact that TEVAR was associated with fivefold less risk of rupture during followup supports its potential positive effect on one of the most important aims of TEVAR, which is preventing aortic rupture. Nonetheless, in those patients treated by TEVAR because of rapid progression with/without ulcer-like projection appearance, it is impossible to demonstrate if, left without TEVAR, they would have developed an aortic event requiring urgent surgery. Last but not least, TEVAR was associated with a trend toward reduced need for (re) intervention if compared to BMT (however, this finding did not quite reach the threshold for significance: RR 0.31 ; 
95\% CI: $0.07-1.45, \mathrm{P}=0.14)$.

Although IMH-B is one pathology of the original triad identified as acute aortic syndrome two decades ago, and despite IMH-B generating a lot of interest across cardiovascular disciplines, currently, evidence does not allow for clear-cut decisions-people must ultimately make them based on clinical experience. Considering the unpredictable behavior and the available results of a selective approach with TEVAR, clinical and morphological details may play a decisive role in surgical decision-making process.

\section{Acknowledgments}

None.

\section{Footnote}

Conflicts of Interest: The authors have no conflicts of interest to declare.

\section{References}

1. Lansman SL, Saunders PC, Malekan R, et al. Acute aortic syndrome. J Thorac Cardiovasc Surg 2010;140:S92-7; discussion S142-6.

2. Mussa FF, Horton JD, Moridzadeh R, et al. Acute Aortic Dissection and Intramural Hematoma: A Systematic Review. JAMA 2016;316:754-63.

3. Ferrera C, Vilacosta I, Gomez-Polo JC, et al. Evolution and prognosis of intramural aortic hematoma. Insights from a midterm cohort study. Int J Cardiol 2017;249:410-3.

4. Yu Y, Fei A, Wu Z, et al. Aortic intramural hemorrhage: A distinct disease entity with mystery. Intractable Rare Dis Res 2017;6:87-94.

5. Evangelista A, Czerny M, Nienaber C, et al. Interdisciplinary expert consensus on management of type $\mathrm{B}$ intramural haematoma and penetrating aortic ulcer. Eur J Cardiothorac Surg 2015;47:209-17.

6. Erbel R, Aboyans V, Boileau C, et al. 2014 ESC Guidelines on the diagnosis and treatment of aortic diseases: Document covering acute and chronic aortic diseases of the thoracic and abdominal aorta of the adult. The Task Force for the Diagnosis and Treatment of Aortic Diseases of the European Society of Cardiology (ESC). Eur Heart J 2014;35:2873-926.

7. Bischoff MS, Meisenbacher K, Wehrmeister M, et al. Treatment indications for and outcome of endovascular repair of type B intramural aortic hematoma. J Vasc Surg 2016;64:1569-1579.e2.

8. Piffaretti G, Lomazzi C, Benedetto F, et al. Best Medical Treatment and Selective Stent-GraftRepair for Acute Type B Aortic Intramural Hematoma. Semin Thorac Cardiovasc Surg 2018;30:279-87.

9. Li DL, Zhang HK, Cai YY, et al. Acute type B aortic intramural hematoma: Treatment strategy and the role of endovascular repair. J Endovasc Ther 2010;17:617-21.

10. Ye K, Qin J, Yin M, et al. Acute Intramural Hematoma of the Descending Aorta Treated with Stent Graft Repair Is Associated with a Better Prognosis. J Vasc Interv Radiol 2017;28:1446-1453.e2.

11. Zhang G, Feng Q, Zheng D, et al. Early aggressive medical treatment associated with selective prophylactic aortic stent-grafting for aortic intramural hematoma. Thorac Cardiovasc Surg 2011;59:342-8.

12. Felisaz A, Dufranc J, Heyndrickx M, et al. Midterm Results of Type B Intramural Hematoma Endovascular Treatment. Ann Vasc Surg 2015;29:898-904.

13. Institute of Health Economics (IHE). Quality Appraisal of Case Series Studies Checklist. Edmonton (AB): Institute of Health Economics; 2014. Available online: http://www. ihe.ca/research-programs/rmd/cssqac/cssqac-about

14. Schoenhoff FS, Zanchin C, Czerny M, et al. Aorta Related and All-cause Mortality in Patients with Aortic Intramural Haematoma. Eur J Vasc Endovasc Surg 2017;54:447-53.

15. Wan X, Wang W, Liu J, et al. Estimating the sample mean and standard deviation from the sample size, median, range and/or interquartile range. BMC Med Res Methodol 2014; $14: 135$.

16. Ioannidis JP, Patsopoulos NA, Evangelou E. Uncertainty in heterogeneity estimates in meta-analyses. BMJ 2007;335:914-6.

17. Anzures-Cabrera J, Higgins J. Graphical displays for metaanalysis: An overview with suggestions for practice. Res Synth Methods 2010;1:66-80.

18. R: A Language and Environment for Statistical Computing [computer program]. R Foundation for Statistical Computing; 2018.

19. Gang L, Dezhi Z, Chen C. The treatment choice and outcome of aortic intramural hematoma. Journal of Cardiovascular and Pulmonary Diseases 2013.

20. Lieming W, Yong Y, Guokai Y, et al. Comparative study of endovascular treatment and conservative treatment of Stanford B aortic intramural hematoma. Chinese Journal of Vascular Surgery 2016;02.

21. Hiratzka LF, Bakris GL, Beckman JA, et al. 2010 ACCF/ AHA/AATS/ACR/ASA/SCA/SCAI/SIR/STS/SVM 
guidelines for the diagnosis and management of patients with thoracic aortic disease: executive summary. A report of the American College of Cardiology Foundation/ American Heart Association Task Force on Practice Guidelines, American Association for Thoracic Surgery, American College of Radiology, American Stroke Association, Society of Cardiovascular Anesthesiologists, Society for Cardiovascular Angiography and Interventions, Society of Interventional Radiology, Society of Thoracic Surgeons, and Society for Vascular Medicine. Catheter Cardiovasc Interv 2010;76:E43-86.

22. Rozado J, Martin M, Pascual I, et al. Comparing American, European and Asian practice guidelines for aortic diseases. J Thorac Dis 2017;9:S551-60.

Cite this article as: Chakos A, Twindyawardhani T, Evangelista A, Maldonado G, Piffaretti G, Yan TD, Tian DH. Endovascular versus medical management of type B intramural hematoma: a meta-analysis. Ann Cardiothorac Surg 2019;8(4):447-455. doi: 10.21037/acs.2019.06.11
23. Piffaretti G, Lomazzi C, Benedetto F, et al. Best Medical Treatment and Selective Stent-GraftRepair for Acute Type B Aortic Intramural Hematoma. Semin Thorac Cardiovasc Surg 2018;30:279-87.

24. Erbel R, Aboyans V, Boileau C, et al. 2014 ESC Guidelines on the diagnosis and treatment of aortic diseases:

Document covering acute and chronic aortic diseases of the thoracic and abdominal aorta of the adult. The Task Force for the Diagnosis and Treatment of Aortic Diseases of the European Society of Cardiology (ESC). Eur Heart J 2014;35:2873-926. 


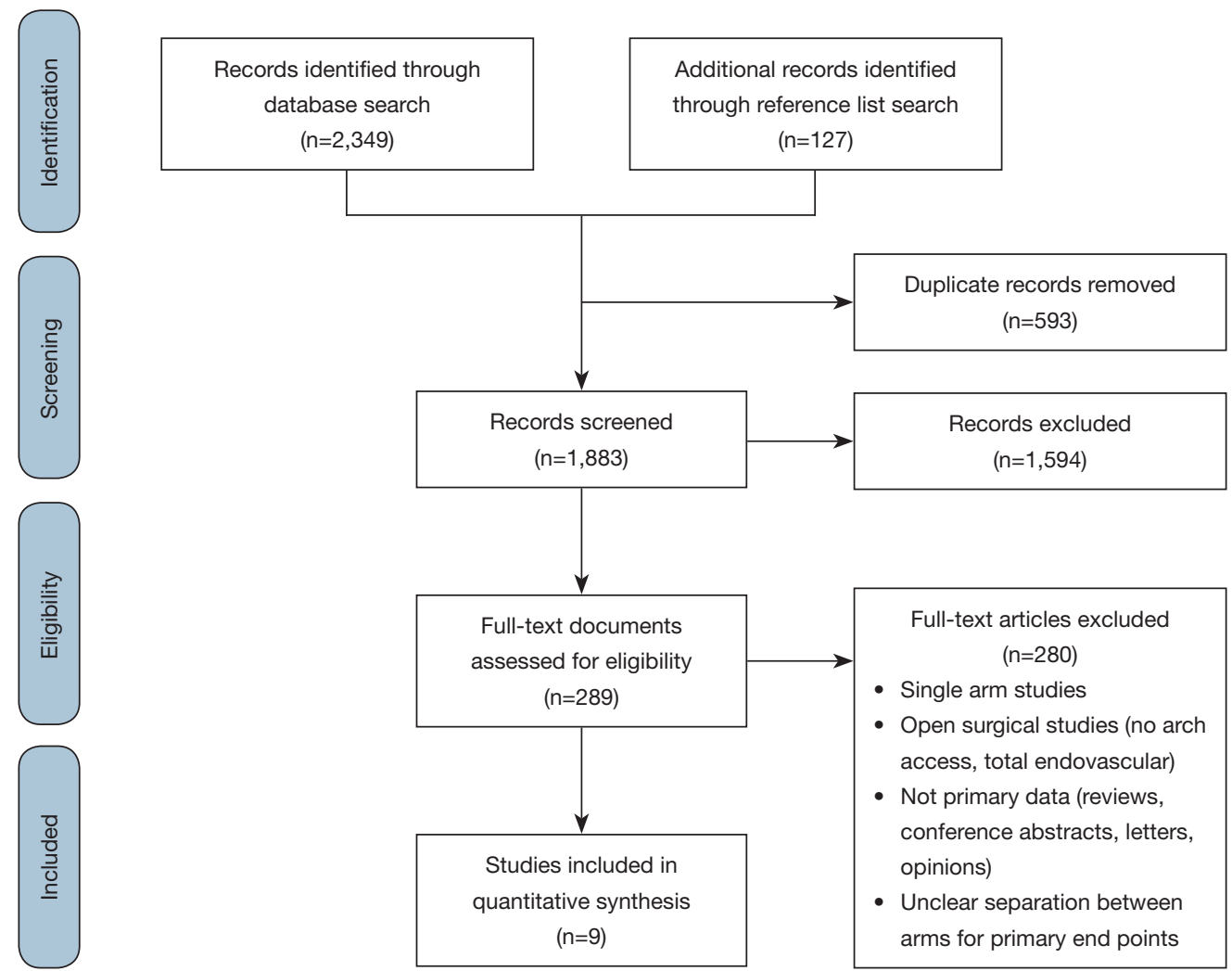

Figure S1 PRIMSA flow chart detailing the literature search process for management of intramural hematoma type B-endovascular versus medical management. IMH-B, type B intramural hematoma.

\begin{tabular}{|c|c|c|c|c|c|c|c|}
\hline \multicolumn{8}{|c|}{ Table S1 Study details } \\
\hline $\begin{array}{l}\text { Author, year of } \\
\text { publication }\end{array}$ & Country & $\begin{array}{l}\text { Recruitment } \\
\text { period }\end{array}$ & $\begin{array}{l}\text { Study } \\
\text { design }\end{array}$ & $\begin{array}{l}\text { IHE } \\
\text { quality }\end{array}$ & Grouping & Patients (n) & Mean f/u (months) \\
\hline \multirow[t]{2}{*}{ Bischoff, 2016} & \multirow[t]{2}{*}{ Germany } & \multirow[t]{2}{*}{ 2004-2014 } & \multirow[t]{2}{*}{$P, S$} & \multirow[t]{2}{*}{$\mathrm{H}$} & TEVAR & 28 & 32 \\
\hline & & & & & MM & 13 & 40 \\
\hline \multirow[t]{2}{*}{ Felisaz, 2015} & \multirow[t]{2}{*}{ France } & \multirow[t]{2}{*}{ 2002-2013 } & \multirow[t]{2}{*}{$\mathrm{R}, \mathrm{S}$} & \multirow[t]{2}{*}{$\mathrm{H}$} & MM & 10 & 46 \\
\hline & & & & & TEVAR & 5 & 46 \\
\hline \multirow[t]{2}{*}{ Li, 2010} & \multirow[t]{2}{*}{ China } & \multirow[t]{2}{*}{ 2001-2009 } & \multirow[t]{2}{*}{$P, S$} & \multirow[t]{2}{*}{$\mathrm{H}$} & TEVAR & 33 & $28 \pm 15$ \\
\hline & & & & & MM & 23 & $28 \pm 15$ \\
\hline \multirow[t]{2}{*}{ Liu, 2013} & \multirow[t]{2}{*}{ China } & \multirow[t]{2}{*}{ 2009-2013 } & \multirow[t]{2}{*}{$\mathrm{R}, \mathrm{S}$} & \multirow[t]{2}{*}{ S } & MM & 7 & 13.3 \\
\hline & & & & & TEVAR & 4 & 13.3 \\
\hline \multirow[t]{2}{*}{ Piffaretti, 2018} & \multirow[t]{2}{*}{ Italy } & \multirow[t]{2}{*}{ 2008-2016 } & \multirow[t]{2}{*}{$\mathrm{R}, \mathrm{Mu}$} & \multirow[t]{2}{*}{$\mathrm{H}$} & $\mathrm{MM}$ & 19 & $40.2 \pm 27.6^{*}$ \\
\hline & & & & & TEVAR & 22 & $40.2 \pm 27.6^{*}$ \\
\hline \multirow[t]{2}{*}{ Schoenhoff, 2017} & \multirow[t]{2}{*}{ Switzerland } & \multirow[t]{2}{*}{ 1999-2013 } & \multirow[t]{2}{*}{$\mathrm{R}, \mathrm{S}$} & \multirow[t]{2}{*}{ M } & $\mathrm{MM}^{\wedge}$ & 25 & $82.8 \pm 43.2$ \\
\hline & & & & & $\mathrm{TEVAR}^{\wedge}$ & 17 & $82.8 \pm 43.2$ \\
\hline \multirow[t]{2}{*}{ Wu, 2016} & \multirow[t]{2}{*}{ China } & \multirow[t]{2}{*}{ 2006-2014 } & \multirow[t]{2}{*}{$\mathrm{S}$} & $\mathrm{S}$ & MM & 34 & - \\
\hline & & & & & TEVAR & 14 & - \\
\hline Ye, 2017 & China & 2006-2015 & $\mathrm{R}, \mathrm{S}$ & $\mathrm{H}$ & TEVAR & 34 & $32 \pm 19$ \\
\hline & & & & & MM & 31 & $32 \pm 19$ \\
\hline Zhang, 2011 & China & $2007-2010$ & $P, S$ & M & MM & 4 & $17.6 \pm 9.9$ \\
\hline & & & & & TEVAR & 4 & $17.6 \pm 9.9$ \\
\hline & & & & & Total & 327 & 37.3 [29-45.5], n=279 \\
\hline
\end{tabular}

*, reported as median with range or interquartile range; $\wedge$, patients were grouped according to the treatment they received in the acute phase for this study; converted to mean \pm standard deviation using methods by Wan et al. IHE (Canadian), Institute for Health Economics; f/u, follow-up; P, prospective; R, retrospective; S, single-centre; Mu, multi-centre; MM, medical management; TEVAR, thoracic endovascular aortic repair; $\mathrm{H}$, high quality; M, moderate quality; S, standard quality. 


\begin{tabular}{|c|c|c|c|c|c|c|}
\hline Characteristic & Total cohort, n (\%, 95\% Cl) & TEVAR, n (\%, 95\% Cl) & $\begin{array}{l}\text { Medical management, n (\%, } \\
95 \% \mathrm{Cl})\end{array}$ & $\mathrm{RD}, \mathrm{MD}(95 \% \mathrm{Cl})$ & $\mathrm{I}^{2}, \%[95 \% \mathrm{Cl}]$ & $\mathrm{P}$ \\
\hline Patients & 327 & 161 & 166 & - & - & - \\
\hline Males & $184 / 271(67,61-72.5)$ & $88 / 121(72.1,61.9-80.4)$ & $61 / 93(65,54.5-74.2)$ & $0.102(-0.0186-0.223)$ & $0[0-0]$ & 0.097 \\
\hline Age, mean (95\% Cl), n (years) & $62.2(55.8-68.7), n=327$ & 62.6 (53.8-71.3), $n=161$ & $61.9(51.7-72.1), n=166$ & $0.495(-1.613-2.602)$ & $0[0-38]$ & 0.645 \\
\hline Hypertension & 179/204 (86, 75.2-92.6) & 72/84 (84.4, 69.3-92.8) & $51 / 63(77.6,56.4-90.3)$ & $0.0322(-0.258-0.322)$ & $82[44-94]$ & 0.828 \\
\hline Diabetes mellitus & $21 / 204(10.7,7.07-15.9)$ & $8 / 84(9.81,4.98-18.4)$ & 7/63 (11.9, 5.75-22.9) & $-0.0080(-0.109-0.0935)$ & $0[0-88]$ & 0.878 \\
\hline COPD & $39 / 162(24.5,15.7-36)$ & $23 / 84(28.1,15.5-45.5)$ & $14 / 63(21.7,7.85-47.4)$ & $0.0767(-0.0505-0.204)$ & 0 [0-62] & 0.237 \\
\hline Ischaemic heart disease & $26 / 139(19.7,11.5-31.8)$ & $10 / 50(20.7,11.5-34.4)$ & $5 / 32(15.6,6.66-32.5)$ & $0.0285(-0.137-0.194)$ & $0[0-0]$ & 0.735 \\
\hline Renal impairment & $16 / 147(12.3,7.63-19.1)$ & 11/84 (13.6, 7.68-23) & $5 / 63(9.53,3.78-22)$ & $0.0517(-0.0386-0.142)$ & $0[0-70]$ & 0.262 \\
\hline History of aortic surgery & $14 / 124(11.8,7.1-19)$ & $4 / 50(8.05,3.05-19.6)$ & 4/32 (13.1, 4.99-30.2) & $-0.0314(-0.163-0.101)$ & $0[0-0]$ & 0.641 \\
\hline Symptomatic presentation & 153/160 (93, 83.1-97.3) & $77 / 80(92.7,82.9-97.1)$ & $76 / 80(93.7,68.3-99)$ & $0.0141(-0.0623-0.0906)$ & $29[0-74]$ & 0.717 \\
\hline Penetrating atheromatous ulcer & $52 / 164(33.4,16.5-55.9)$ & $51 / 117(51.2,27.3-74.6)$ & $1 / 47(7.3,2.05-22.8)$ & $0.565(0.240-0.889)$ & 85 [63-94] & 0.001 \\
\hline Ulcer-like projection & $18 / 97(19.7,9.89-35.5)$ & $16 / 55(29.7,19-43.3)$ & 2/42 (5.94, 1.73-18.5) & $0.240(0.0965-0.384)$ & 0 [0-89] & 0.001 \\
\hline MAD, mean $(95 \% \mathrm{Cl}), \mathrm{n}(\mathrm{mm})$ & 40.4 (37.1-43.8), $n=213$ & 40.8 (36.7-44.8), $n=117$ & 37.3 (33.4-41.3), n=86 & $3.46(-2.02-8.93)$ & $81[41-94]$ & 0.216 \\
\hline IMH size, mean (95\% Cl), $\mathrm{n}(\mathrm{mm})$ & $13.1(10.1-16), n=213$ & 15.9 (13-18.8), n=117 & 10.5 (7.66-13.3), $n=86$ & $5.47(0.320-10.6)$ & 92 [79-97] & 0.037 \\
\hline
\end{tabular}

Table S3 Patient presentation and baseline risk data

\begin{tabular}{|c|c|c|c|c|c|c|c|c|c|c|c|c|c|c|c|c|}
\hline $\begin{array}{l}\text { Author, year of } \\
\text { publication }\end{array}$ & Grouping & $\begin{array}{l}\text { Patients } \\
\text { (n) }\end{array}$ & $\begin{array}{l}\text { Males } \\
\text { (n) }\end{array}$ & Age & $\begin{array}{l}\text { Symptomatic } \\
\text { presentation } \\
\text { (n) }\end{array}$ & $\begin{array}{l}\text { Max aortic } \\
\text { diameter } \\
(\mathrm{mm})\end{array}$ & $\begin{array}{l}\text { IMH size } \\
(\mathrm{mm})\end{array}$ & $\begin{array}{l}\text { PAU } \\
\text { (n) }\end{array}$ & $\begin{array}{l}\text { ULP } \\
\text { (n) }\end{array}$ & $\begin{array}{l}\text { Smoker } \\
\text { (n) }\end{array}$ & $\begin{array}{l}\text { HTN } \\
(n)\end{array}$ & $\begin{array}{l}\text { DM } \\
\text { (n) }\end{array}$ & $\begin{array}{l}\text { COPD } \\
\text { (n) }\end{array}$ & $\begin{array}{l}\text { IHD } \\
\text { (n) }\end{array}$ & $\begin{array}{l}\text { Renal } \\
\text { impairment } \\
\text { (n) }\end{array}$ & $\begin{array}{l}\text { Hx aortic } \\
\text { surgery (n) }\end{array}$ \\
\hline \multirow[t]{2}{*}{ Bischoff, 2016} & TEVAR & 28 & 16 & $68.0 \pm 12.7^{*}$ & 25 & $46.4 \pm 12.1^{*}$ & $18.7 \pm 9.6^{\star}$ & 6 & 6 & 19 & 27 & 2 & 6 & 7 & 5 & 2 \\
\hline & MM & 13 & 6 & $65.2 \pm 11.2^{*}$ & 9 & $38.1 \pm 7.0^{*}$ & $11.5 \pm 4.6^{*}$ & 0 & 1 & 4 & 9 & 2 & 1 & 2 & 1 & 1 \\
\hline \multirow[t]{2}{*}{ Felisaz, 2015} & MM & 10 & 10 & $67.3 \pm 13.3$ & 10 & $50 \pm 8$ & $12.2 \pm 4.1$ & & 0 & 8 & 15 & 2 & 2 & 7 & & \\
\hline & TEVAR & 5 & & & 5 & & & & 2 & & & & & & & \\
\hline \multirow[t]{2}{*}{ Li, 2010} & TEVAR & 33 & 24 & $59.7 \pm 15.3^{*}$ & 33 & 40 & 10 & 14 & & & & & & & & \\
\hline & MM & 23 & 15 & $56.0 \pm 15.6^{*}$ & 23 & 37 & 8 & 0 & & & & & & & & \\
\hline \multirow[t]{2}{*}{ Liu, 2013} & MM & 7 & 6 & $58.6 \pm 13.2$ & & & & 0 & & & & & & & & \\
\hline & TEVAR & 4 & 4 & & & & & 4 & & & & & & & & \\
\hline \multirow[t]{2}{*}{ Piffaretti, 2018} & MM & 19 & 12 & $73 \pm 9$ & & $40 \pm 6$ & $12 \pm 3$ & & 1 & & 19 & 1 & 8 & 3 & 3 & 3 \\
\hline & TEVAR & 22 & 17 & $69 \pm 10$ & & $38 \pm 7$ & $13 \pm 5$ & & 8 & & 17 & 3 & 10 & 3 & 3 & 2 \\
\hline \multirow{2}{*}{$\begin{array}{l}\text { Schoenhoff, } \\
2017\end{array}$} & $\mathrm{MM}^{\wedge}$ & 25 & 25 & $70.8 \pm 9.5$ & & & & & & 21 & 41 & 4 & & 4 & & 6 \\
\hline & TEVAR $^{\wedge}$ & 17 & & & & & & & & & & & & & & \\
\hline \multirow[t]{2}{*}{ Wu, 2016} & MM & 34 & & $41.2 \pm 5.6$ & 34 & & & & & & & & & & & \\
\hline & TEVAR & 14 & & & 14 & & & 14 & & & & & & & & \\
\hline \multirow[t]{2}{*}{ Ye, 2017} & TEVAR & 34 & 27 & $64.5 \pm 11.2$ & & $39.1 \pm 7$ & $16.6 \pm 4$ & 9 & & 25 & 28 & 3 & 7 & & 3 & \\
\hline & MM & 31 & 22 & $61.2 \pm 9.7$ & & $34.3 \pm 5$ & $8.3 \pm 2$ & & & 24 & 23 & 4 & 5 & & 1 & \\
\hline \multirow[t]{2}{*}{ Zhang, 2011} & MM & 4 & & $64.4 \pm 10.2$ & & & & 1 & & & & & & & & \\
\hline & TEVAR & 4 & & & & & & 4 & & & & & & & & \\
\hline
\end{tabular}

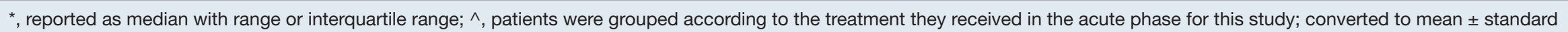

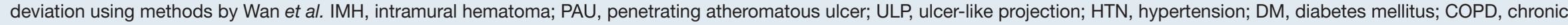
obstructive pulmonary disease; IHD, ischaemic heard disease; MM, medical management; TEVAR, thoracic endovascular aortic repair. 


\begin{tabular}{|c|c|c|c|c|c|c|c|c|c|c|c|c|}
\hline $\begin{array}{l}\text { Author, year } \\
\text { of publication }\end{array}$ & Grouping & $\begin{array}{l}\text { Patients } \\
\text { (n) }\end{array}$ & $\begin{array}{l}\text { Operation } \\
\text { time (min) }\end{array}$ & $\begin{array}{l}\text { Contrast } \\
\text { load (mL) }\end{array}$ & $\begin{array}{l}\text { CSF } \\
\text { drained } \\
\text { (n) }\end{array}$ & $\begin{array}{l}\text { Number } \\
\text { stents (n) }\end{array}$ & $\begin{array}{l}\text { Device types } \\
\text { (descriptive) }\end{array}$ & $\begin{array}{l}\text { LSubC } \\
\text { coverage } \\
\text { (n) }\end{array}$ & $\begin{array}{l}\text { LSubC } \\
\text { revascularised } \\
\text { (n) }\end{array}$ & $\begin{array}{l}\text { Zone } 2-5 \\
\text { coverage } \\
\text { (n) }\end{array}$ & $\begin{array}{l}\text { Zone 3-5 } \\
\text { coverage } \\
\text { (n) }\end{array}$ & $\begin{array}{l}\text { Zone 4+ } \\
\text { coverage } \\
\text { (n) }\end{array}$ \\
\hline \multirow[t]{2}{*}{$\begin{array}{l}\text { Bischoff, } \\
2016\end{array}$} & TEVAR & 28 & $118.5 \pm 76.3^{*}$ & $126.8 \pm 60.8^{*}$ & 13 & $2.0 \pm 0.6^{*}$ & $\begin{array}{l}\text { GORE, Valiant } \\
\text { (Medtronic), } \\
\text { Talent } \\
\text { (Medtronic) }\end{array}$ & 10 & 5 & 9 & 14 & 5 \\
\hline & MM & 13 & - & & & & & & & & & \\
\hline \multirow[t]{2}{*}{ Felisaz, 2015} & MM & 10 & & & & & & & & & & \\
\hline & TEVAR & 5 & & & & & $\begin{array}{l}\text { Talent (1), } \\
\text { Zenith (9) }\end{array}$ & 1 & 3 & 3 & 6 & \\
\hline \multirow[t]{2}{*}{ Li, 2010} & TEVAR & 33 & & & & & $\begin{array}{l}\text { Talent } \\
\text { (Medtronic), } \\
\text { Hercules } \\
\text { (MicroPort } \\
\text { China) }\end{array}$ & & & & & \\
\hline & MM & 23 & & & & & & & & & & \\
\hline \multirow[t]{2}{*}{ Liu, 2013} & MM & 7 & & & & & & & & & & \\
\hline & TEVAR & 4 & & & & & & & & & & \\
\hline \multirow{2}{*}{$\begin{array}{l}\text { Piffaretti, } \\
2018\end{array}$} & MM & 19 & & & & & & & & & & \\
\hline & TEVAR & 22 & $115 \pm 58$ & $104 \pm 46$ & 7 & $1.3 \pm 0.3^{*}$ & & 6 & 5 & & & \\
\hline \multirow{2}{*}{$\begin{array}{l}\text { Schoenhoff, } \\
2017\end{array}$} & $\mathrm{MM}^{\wedge}$ & 25 & & & & & & & & & & \\
\hline & $\mathrm{TEVAR}^{\wedge} \wedge$ & 17 & & & & & & & & & & \\
\hline \multirow[t]{2}{*}{ Wu, 2016} & MM & 34 & & & & & & & & & & \\
\hline & TEVAR & 14 & & & & & & & & & & \\
\hline \multirow[t]{2}{*}{ Ye, 2017} & TEVAR & 34 & $88 \pm 26$ & & 4 & $2 \pm 0.4$ & $\begin{array}{l}\text { Gore (20), } \\
\text { Zenith (11), } \\
\text { Valiant (8) }\end{array}$ & & & 16 & 23 & \\
\hline & MM & 31 & & & & & & & & & & \\
\hline \multirow[t]{2}{*}{ Zhang, 2011} & $\mathrm{MM}$ & 4 & & & & & & & & & & \\
\hline & TEVAR & 4 & & & & & & & & & & \\
\hline
\end{tabular}

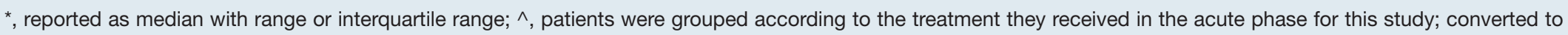

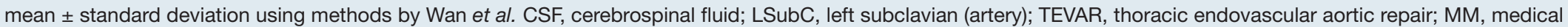
management. 


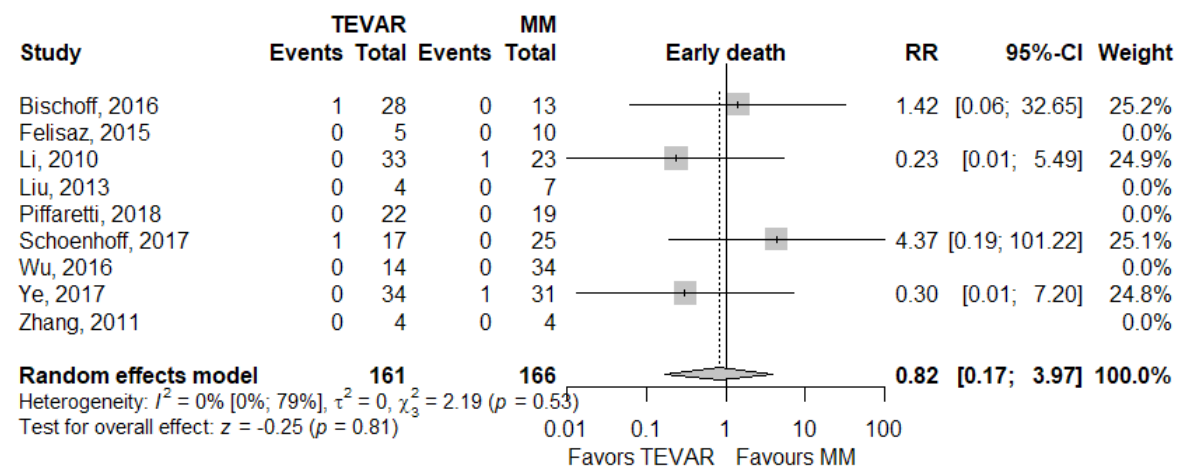

Figure S2 Secondary endpoint of early death (in-hospital or 30-day mortality).

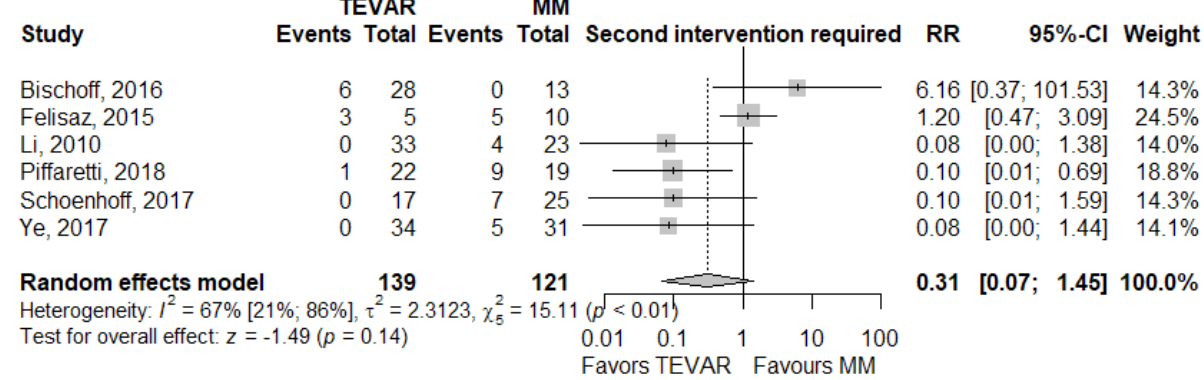

Figure S3 Secondary endpoint of requirement for second intervention (after index medical management or TEVAR procedure). TEVAR, thoracic endovascular aortic repair. 


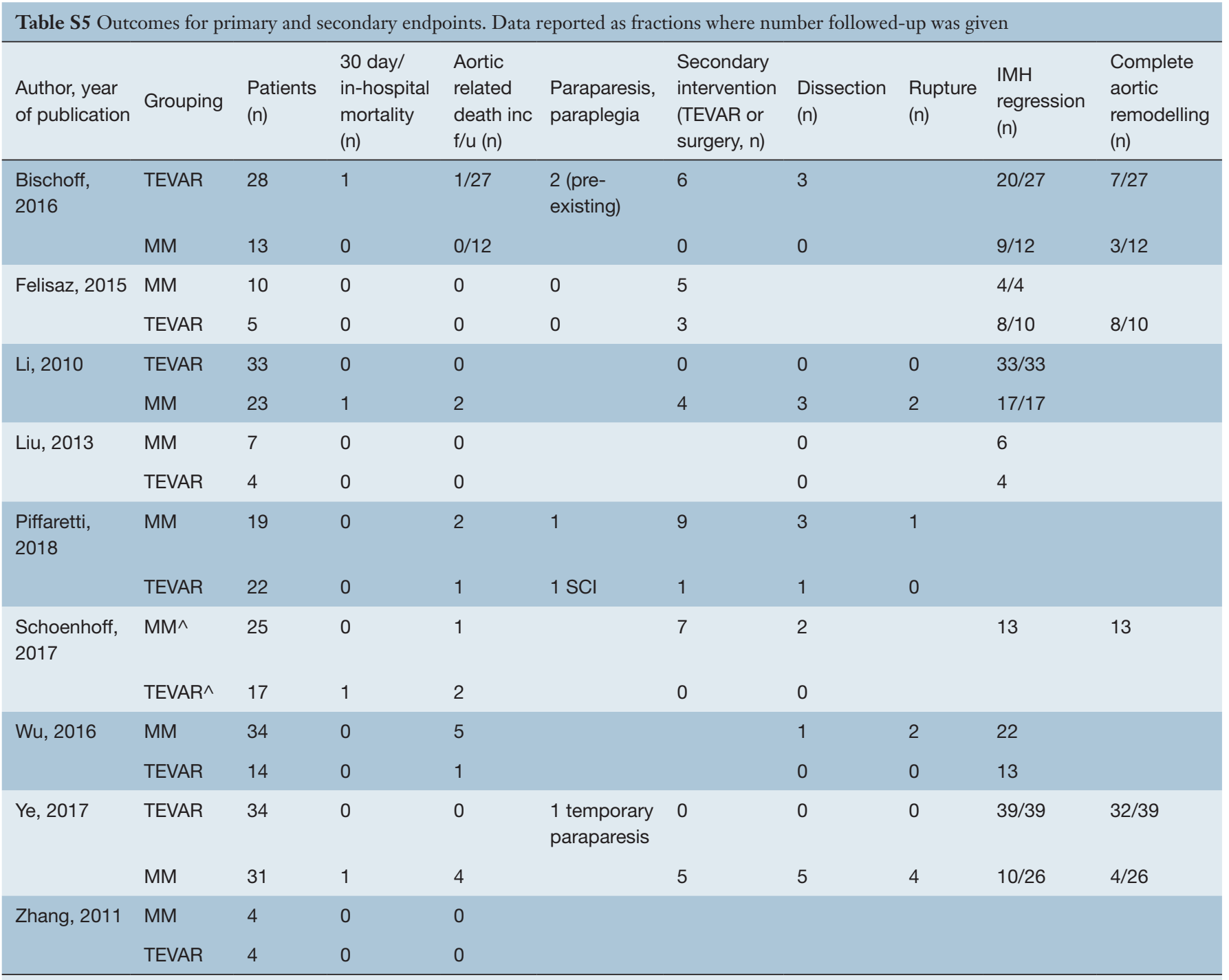

TEVAR, thoracic endovascular aortic repair; $\wedge$, patients were grouped according to the treatment they received in the acute phase for this study. MM, medical management; inc f/u, including at follow-up; IMH, intramural hematoma. 


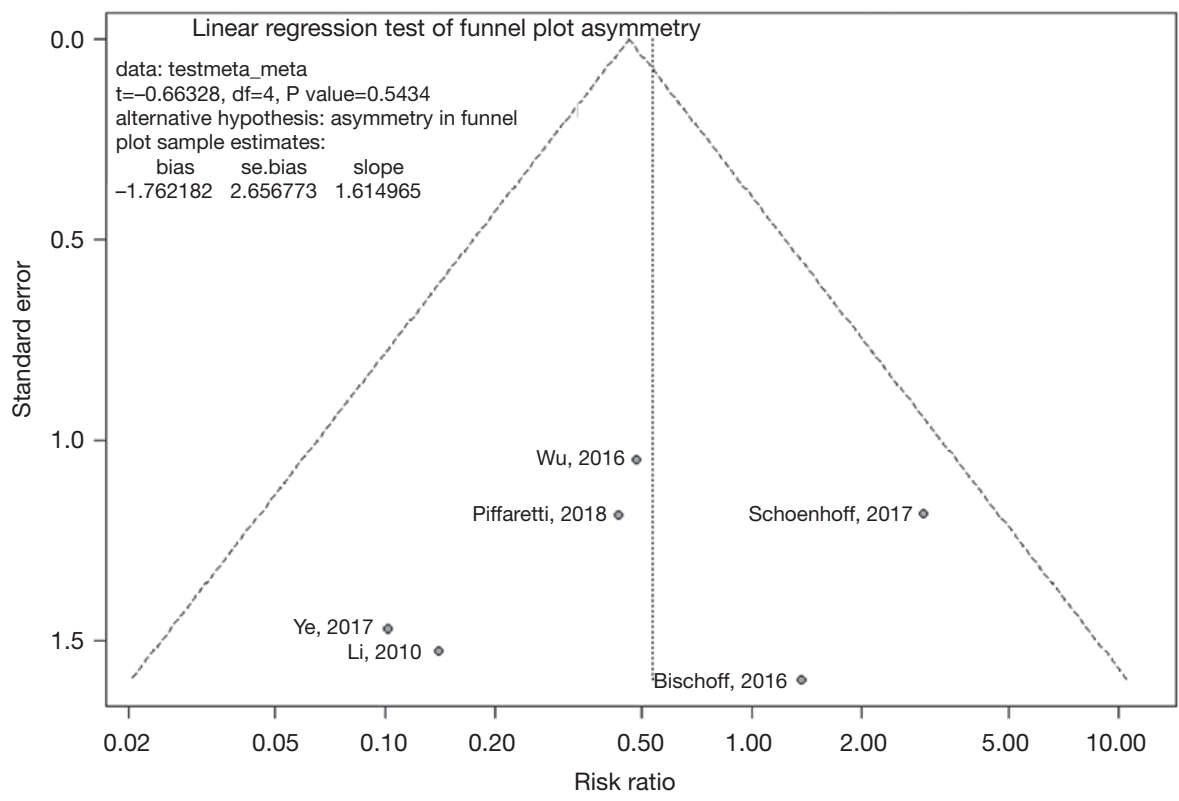

Figure S4 Funnel plot and results of Egger's test to examine for publication bias for the primary endpoint of aortic-related death. Egger's test indicates that the null hypothesis of symmetry cannot be rejected given $\mathrm{P}>0.05$. Note that zero event studies are not included.

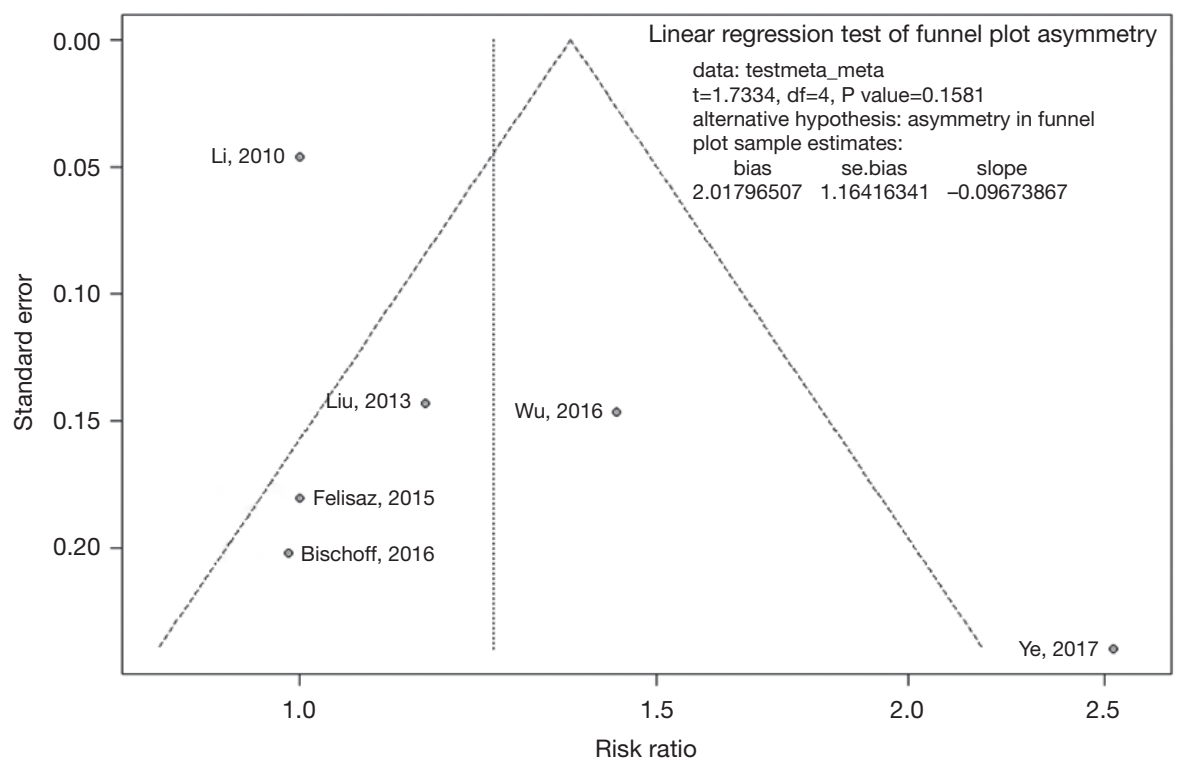

Figure S5 Funnel plot and results of Egger's test to examine for publication bias for the primary endpoint of IMH-B regression. Egger's test indicates that the null hypothesis of symmetry cannot be rejected given $\mathrm{P}>0.05$. Note that zero event studies are not included. IMH-B, type B intramural hematoma. 